\title{
DETECÇÃO DIRETA E EVIDÊNCIA DE EXPOSIÇÃO À ANAPLASMA PHAGOCYTOPHILUM EM EQUINOS DE MINAS GERAIS, BRASIL.
}

\author{
ANAPLASMA PHAGOCYTOPHILUM DIRECT DETECTION AND EXPOSURE EVIDENCE IN \\ EQUINES FROM MINAS GERAIS, BRAZIL.
}

\author{
L. G. PRADO ${ }^{1}$, M. S. PALHARES ${ }^{2}$, A. L. S. MIRANDA ${ }^{3}$, M. F. B. RIBEIRO ${ }^{4}$, \\ J. A. G. SILVEIRA ${ }^{5}$, C. V. BASTOS
}

\section{RESUMO}

A Anaplasmose Granulocítica Equina (AGE) é causada pelo Anaplasma phagocytophilum, bactéria intracelular obrigatória, Gram-negativa, membro da família Anaplasmataceae incluída na ordem das Rickettsiales. Pouco se sabe sobre a doença, dinâmica de transmissão, cepa e prevalência da doença no território brasileiro. O presente trabalho teve por objetivo verificar, por métodos diretos e sorológicos, a ocorrência de A. phagocytophilum em equinos no municípios de Belo Horizonte, Minas Gerais. Encontrou-se uma ocorrência ao exame da reação de imunofluorescência indireta (RIFI) de 53,57\% (120/224). Ao exame de capa leucocitária foi encontrado um percentual de 3,14\% (7/223) de animais positivos. A maioria das amostras $(41,47 \%)$ apresentou uma diluição de 1:160, tais amostras foram então submetidas à titulação nas diluições de 1:320, 1:640 e 1:1280. Pode-se concluir que a infecção por A. phagocytophilum está presente em cavalos pertencentes ao "Projeto Carroceiros" no município de Belo Horizonte. Para que se entenda melhor qual a importância epidemiológica desta infecção para o município mais levantamentos sorológicos e moleculares, em equinos, devem ser realizados a fim de se entender melhor a dinâmica do agente na população equina.

PALAVRAS-CHAVE: Epidemiologia. Imunofluorescência Indireta. Capa Leucocitária. Anaplasmose equina.

\section{SUMMARY}

Equine granulocytic anaplasmosis is caused by Anaplasma phagocytophilum, a gram negative, obligatory intracellular bacteria, member of Anaplasmataceae family, included in the Rickettsiales order. Little is known about the disease, transmission dynamics, strain and prevalence in Minas Gerais State. This work aimed to verify, using direct and serologic methods, the occurrence of A. phagocytophilum in equines of the municipality of Belo Horizonte, Minas Gerais. It was found a positive reaction in the IFA in a frequency of $53.57 \%(120 / 124)$. In the buffy coat evaluation, it was found a percentage of $3.14 \%$ (7/223) of positive animals. Most of the samples reacted at a 1:160 dilution and were submitted to titration in the dilutions of 1:320, 1:640 and 1:1280. It is possible to conclude that A. phagocytophilum infection is present in horses of "Projeto Carroceiros" of the municipality of Belo Horizonte. In order to better understand the epidemiological importance of this infection more studies are needed to comprehend the dynamic of the agent in the equine population.

KEY-WORDS: Epidemiology. Indirect Immunofluorescence. Buffy coat. Regionals.

\footnotetext{
${ }^{1}$ Médico Veterinário autônomo. CRMV-SP 41758.

${ }^{2}$ Professora da Escola de Veterinária da Universidade Federal de Minas Gerais.

${ }^{3}$ Estudante de Doutorado em Ciência Animal, Escola de Veterinária da Universidade Federal de Minas Gerais.

${ }^{4}$ Professor do Instituto de Ciências Biológicas da Universidade Federal de Minas Gerais.

${ }^{5}$ Professora do Instituto de Ciências Biológicas da Universidade Federal de Minas Gerais.

${ }^{6}$ Professora da Escola de Veterinária da Universidade Federal de Minas Gerais.
} 


\section{INTRODUÇ̃̃O}

A Anaplasmose Granulocítica Equina (AGE) é causada pelo $A$. phagocytophilum, bactéria intracelular obrigatória, Gram-negativa, membro da família Anaplasmataceae incluída na ordem das Rickettsiales (MEZERVILLE E PADILLA-CUADRA, 2007). Baseados em análises no RNA ribossômico $16 \mathrm{~S}$ e no gene groESL, na presença de antígenos e características biológicas comuns, o agente da Erliquiose Granulocítica Humana (EGH), Ehrlichia equi, agente da Erliquiose Granulocítica Equina (EGE), e Ehrlichia phagocytophila, agente da Febre do Carrapato em ruminantes, foram reagrupadas em uma única espécie: A. phagocytophilum (DUMLER et al., 2001; VON LOEWENICH et al., 2003). A bactéria infecta leucócitos polimorfonucleares do hospedeiro, principalmente os neutrófilos (CARLYON E FIKRING, 2003).

O agente se mantém na natureza de forma cíclica, alternando-se entre vetor (carrapatos ixodídeos) e mamíferos suscetíveis (CARLYON E FIKRING, 2003). Além dos equídeos, os ruminantes, roedores, canídeos, aves e seres humanos são possíveis hospedeiros da bactéria (DE LA FUENTE et al., 2005). O aumento do contato entre animais selvagens, domésticos e seres humanos eleva o risco de surtos de doenças transmitidas por carrapatos, dentre elas a anaplasmose. Esse contato estreito entre animais e seres humanos torna difícil a implementação de programas de controle tanto do vetor quanto da doença (DE LA FUENTE et al., 2005).

A primeira descrição em equinos foi realizada em 1969 na Califórnia, Estados Unidos (GRIBBLE, 1969; STANNARD et al., 1969) e em seres humanos em 1994, também nos Estados Unidos (BAKKEN et al., 1994). Em equinos, já foi descrito caso clínico na Alemanha (VON LOEWENICH et al., 2003) e Holanda (BUTLER et al., 2008) e levantamentos sorológicos foram realizados no Brasil (SALVAGNI et al., 2010), Dinamarca (HANSEN et al., 2010), Espanha (DE LA FUENTE et al., 2005), Suíça (PUSTERLA et al., 1999), Itália (GIUDICE et al., 2012), França (LEBLOND et al., 2005), Portugal (RIBEIRO et al., 2013), República Tcheca (PRASKOVA et al., 2011)

No Brasil, por se tratar de uma doença emergente, pouco se sabe sobre sua epidemiologia, fisiopatologia e transmissão. Há pesquisas soroepidemiológicas nos estados de Minas Gerais (Gavião Prado et al., 2011), Goiás e Distrito Federal (Salvagni et al., 2010). Em um levantamento clínico sorológico na região centro - oeste do Brasil, Salvagni et al. (2010) encontraram uma prevalência de $65 \%$ de equinos positivos para A. phagocytophilum pelo teste de ELISA. Apesar disto, nenhum equino foi positivo pelo exame microscópico de capa leucocitária ou nested PCR (nPCR). Já Gavião Prado et al. (2011), em estudo feito com equídeos de tração da região metropolitana de Belo Horizonte, apesar de terem encontrado soroprevalência semelhante $(64,91 \%)$, obtiveram resultado de $28,06 \%$ de animais positivos pelo exame microscópico de capa leucocitária. Além disso, existem relatos da detecção do agente em animais domésticos e silvestres em todo o território nacional (SANTOS et al., 2013; ANDRÉ et al., 2014; MONGRUEL et al., 2017).

A anaplasmose granulocítica é caracterizada por sinais clínicos de hipertermia, anorexia, depressão, edema de membros, ataxia e baixa mortalidade. Corpúsculos de inclusão em neutrófilos, leucopenia, trombocitopenia e anemia leve são as alterações hematológicas mais relatadas (GRIBBLE, 1969; SALVAGNI et al., 2010).

O diagnóstico da AGE é realizado por meio dos sinais clínicos e presença de inclusões intracitoplasmáticas em granulócitos, principalmente neutrófilos (STANNARD et al., 1969; DE LA FUENTE et al., 2005; SALVAGNI et al., 2010). Métodos sorológicos e moleculares como ELISA, Reação de Imunofluorescência indireta (RIFI) e Reação em Cadeia de Polimerase (PCR) também são utilizados para diagnóstico do agente (DE LA FUENTE et al., 2005; HANSEN et al., 2010; SALVAGNI et al., 2010).

Segundo Silaghi et al. (2017) o diagnóstico realizado por meio da avaliação de esfregaços de capa leucocitária utilizando microscopia óptica é o método mais rápido e barato com o problema de ser de baixa sensibilidade e depender da experiência do observador, assim, casos considerados negativos por este método devem ser avaliados em conjunto com outros métodos como o sorológico e molecular.

A reação de Imunofluorescência indireta é considerado um bom método de diagnóstico para o $A$. phagocytophilum, apesar de possuir uma sensibilidade e especificidade mais baixas, quando comparado ao ELISA (ZIMMERMAN E CRISMAN, 2008). Já a utilização da PCR tem se mostrado indispensável do diagnóstico da infecção pelo agente. Atualmente, há um aumento significativo de protocolos de alta performance e PCR multiplex que aumentam a chance de um diagnóstico mais preciso (SILAGHI et al., 2017).

O presente trabalho teve por objetivo verificar, por métodos diretos e sorológicos, a ocorrência de $A$. phagocytophilum em equinos no municípios de Belo Horizonte, Minas Gerais.

\section{MATERIAL E MÉTODOS}

O experimento foi conduzido de acordo com os conceitos e preceitos éticos, após aprovação no CEUA UFMG sob protocolo $\mathrm{n}^{\circ} 167 / 2013$. Os proprietários assinaram termo de consentimento para utilização dos animais nesta pesquisa.

Foram utilizados 224 animais de tração oriundos de Belo Horizonte, Minas Gerais. Do total de 224 animais avaliados, 41,07\% (92/224) eram fêmeas e $58,93 \%$ (132/224) eram machos. Tais animais são pertencentes aos carroceiros do município, devidamente inscritos no projeto de extensão "Correção Ambiental e Reciclagem com Carroceiros de Belo Horizonte" (Projeto Carroceiros).

O município de Belo Horizonte é dividido, desde 1983, em nove unidades administrativas, denominadas Regionais. As amostras utilizadas no estudo são provenientes de oito Regionais Administrativas, com exceção da Regional Centro-Sul, devido ao fato de os 
carroceiros serem proibidos de circularem dentro do perímetro urbano delimitado pela Avenida do Contorno.

Não foi realizada avaliação clínica dos animais nem avaliação para a presença de carrapatos nos mesmos. Durante as visitas às Regionais são realizados questionários sócio-econômicos sobre os carroceiros e questionários sobre o manejo dos animais e consta dentre as perguntas, questões sobre o controle de carrapatos dos animais avaliados.

Foram utilizadas amostras de soro e sangue total oriundas de visitas realizadas durante os anos de 2010, 2011 e 2012. A coleta do sangue foi realizada por meio de venulopunção da jugular externa, após contenção dos animais em tronco e antissepsia do local, utilizando algodão embebido em álcool 70\%. Foram coletados dois tubos a vácuo, sendo um deles sem anticoagulante e outro contendo ácido etilenodiamonio tetra-acético (EDTA).

Foram confeccionadas lâminas de esfregaço de capa leucocitária a partir do sangue total coletado em tubos contendo EDTA e, após centrifugação dos tubos sem anticoagulante, o sobrenadante foi armazenado em tubos próprios para congelamento. As amostras, após processamento, foram armazenadas em freezer a $-20^{\circ} \mathrm{C}$ até o momento das análises.

Lâminas de vidro próprias para RIFI, contendo 12 poços que foram previamente fixados com o antígeno proveniente do cultivo de Anaplasma phagocytophilum mantido em IDE8 no Laboratório de Protozoologia do Instituto de Ciências Biológicas da Universidade Federal de Minas Gerais. A técnica utilizada para fabricação e fixação do antígeno foi adaptada da descrita por Aguiar et al. (2007).

Após padronização prévia da técnica (SIVEIRA et al., 2017), as amostras foram diluídas na proporção de 1:160, para se evitar a ocorrência de reações inespecíficas, em salina fosfatada tamponada 1x (PBS $1 \mathrm{x})$, que foi considerado o ponto de corte para a análise. Após a triagem, as amostras consideradas positivas, foram novamente diluídas para se avaliar a titulação do IgG desses animais. As diluições utilizadas foram 1:320, $1: 640$ e $1: 1280$.

Como controle positivo foi utilizado o soro de um animal conhecidamente positivo após a realização de testes RIFI (GAVIÃO PRADO et al., 2014), para a confirmação da positividade do soro deste animal, uma amostra de sangue total foi submetida à reação em cadeia da polimerase (PCR). Como controle negativo foi utilizado soro de um animal do mesmo trabalho citado e foram utilizados os mesmos métodos para confirmação da negatividade da amostra.

A leitura das lâminas de RIFI foi realizada em microscópio de fluorescência por apenas um avaliador para se evitar diferentes interpretações dos resultados. As reações consideradas positiva e negativa são demonstradas na Figura 1.

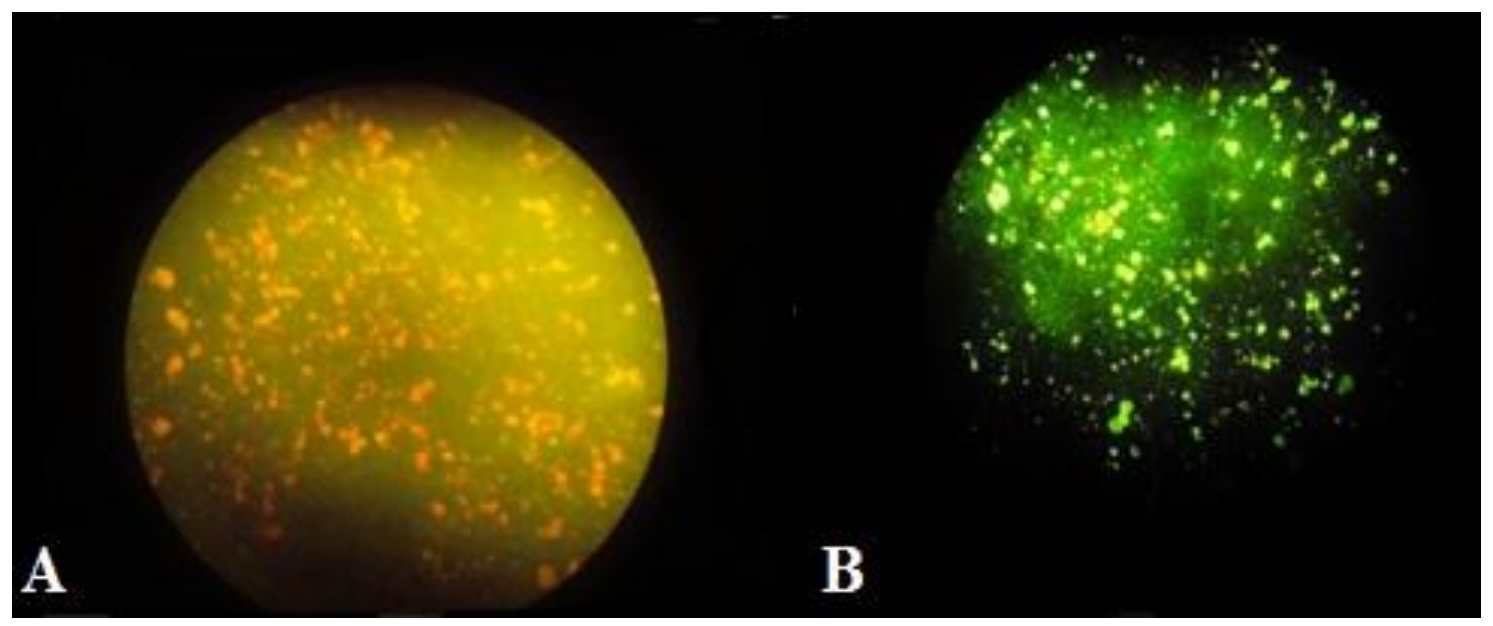

Figura 1 - A: Reação de Imunofluorescência Indireta negativa. Observar as células IDE8 contendo inclusões de $A$. phagocytophilum sem ligação do conjugado. B: Reação de Imunofluorescência Indireta positiva. Observar fluorescência do conjugado ligado à membrana citoplasmática do A. phagocytophilum. Aumento: 400x

Dentre as 224 amostras utilizadas para a avaliação sorológica e avaliação da capa leucocitária foram escolhidas aleatoriamente 96 amostras para a realização do exame molecular, utilizando a técnica de nested PCR, preconizada por Silaghi (2012).

Os dados foram tabulados no programa Excel® e analisados pelo programa estatístico SAS (2003). Os dados apresentaram distribuição não paramétrica e foram submetidos a transformação pelo $\log (x+1)$ e os percentuais pelo Arco seno $\sqrt{x}$. Após transformação, os dados permaneceram com distribuição não paramétrica.
Desta forma, as médias foram comparadas pelo teste de Wilcoxon ou pelo teste de Kruskal-Wallis.

\section{RESULTADOS E DISCUSSAO}

Encontrou-se uma ocorrência de 53,57\% (120/224) de animais positivos à diluição de 1:160. Foram observadas variações estatisticamente significativas $(\mathrm{p}<0,05)$ entre as frequências da regional Oeste e Venda Nova e entre as Regionais Venda Nova e Leste, Nordeste, Barreiro, Noroeste, Norte e Pampulha. A distribuição de animais, de acordo com as regionais, está apresentada na Tabela 1 . 
Tabela 1 - Distribuição da frequência de animais reagentes para Anaplasma phagocytophilum de acordo com a Regional Administrativa de Belo Horizonte.

\begin{tabular}{lcc}
\hline Regional & \multicolumn{2}{c}{ Amostras Reativas } \\
\cline { 2 - 3 } Barreiro & \% & $\mathbf{n}$ \\
\cline { 2 - 3 } Leste & $45,00^{\mathrm{C}}$ & $(9 / 20)$ \\
Nordeste & $56,67^{\mathrm{BC}}$ & $(17 / 30)$ \\
Noroeste & $50,00^{\mathrm{C}}$ & $(13 / 30)$ \\
Norte & $43,33^{\mathrm{C}}$ & $(12 / 30)$ \\
Oeste & $40,00^{\mathrm{C}}$ & $(20 / 24)$ \\
Pampulha & $83,33^{\mathrm{A}}$ & $(11 / 30)$ \\
Venda Nova & $36,67^{\mathrm{C}}$ & $(23 / 30)$ \\
& $76,67^{\mathrm{AB}}$ & $\mathbf{( 1 2 0 / 2 2 4})$ \\
\hline
\end{tabular}

Percentuais seguidos por letras diferentes, na mesma coluna, diferem $(\mathrm{p}<0,05)$.

Salvagni et al. (2010) encontraram uma ocorrência de $90 \%$ de animais positivos para a infecção por A. phagocytophilum utilizando a técnica de RIFI, na região Centro-oeste do Brasil. Apesar de apresentar uma porcentagem maior de animais positivos em relação ao presente trabalho, os autores utilizaram um número de animais menor (20 animais), o que pode ter influenciado nesta maior porcentagem.

A possibilidade de ocorrência de reação cruzada com outras espécies de hemoparasitas foi considerada no presente estudo, a fim de se reduzir essa ocorrência, optou-se por elevar o ponto de corte da RIFI no momento da triagem. Ferreira et al. (2008) descrevem esta reação cruzada ao avaliarem cães PCR-positivos para Anaplasma platys utilizando ELISA comercial destinado a detectar anticorpos anti- $A$. phagocytophilum. Isso mostra que pode haver reação para RIFI positivo em animais infectados por outros agentes pertencentes à família Anaplasmataceae.

Na República Tcheca, Praskova et al. (2011) encontraram uma prevalência de $73 \%$ de animais positivos para a infecção pelo agente, neste estudo foram utilizados 96 animais aparentemente saudáveis. Os autores consideraram que a alta ocorrência desta afecção no país é devido a cronicidade de doença nos animais, fazendo com o que os mesmos não apresentem sinais clínico, mas sejam considerados positivos ao exame da RIFI. Apesar de a ocorrência encontrada no presente estudo ter sido menor, a possibilidade de haver animais cronicamente infectados deve ser levada em consideração, uma vez que os valores para RIFI e para capa leucocitária serem diferentes, e maiores para a RIFI.

Já Hansen et al. (2010) encontraram, na Dinamarca, valores menores que aqueles encontrados pelo presente trabalho. Os autores encontraram uma prevalência de $22,3 \%$ de animais positivos para a infecção por A. phagocytophilum. Diferentemente aos autores do presente trabalho, eles utilizaram o ELISA como método sorológico para a detecção de anticorpos anti-A.phagocytophilum em 390 equinos. A maior ocorrência de encontrada neste trabalho se deve à maior exposição dos animais à fatores de risco para a doença, como a presença de carrapatos Ixodideos nos locais de coleta, além disso, quando perguntados sobre controle de carrapatos, os proprietários dos animais relatam que o mesmo não é realizado ou é feito de maneira incorreta não garantindo que os animais estejam protegidos de infestações e possível transmissão do agente.

As Regionais Oeste e Venda Nova apresentaram grande número de animais positivos com titulação predominantemente entre 1:160 e 1:320. Nas Regionais Leste e Norte, houve uma alta ocorrência de animais com título acima de 1:640. A distribuição das titulações de acordo com as Regionais está apresentada na Tabela 2.

Tabela 2 - Distribuição das amostras reativas na RIFI, de acordo com a Regional e a diluição do soro, em investigação da ocorrência de Anaplasma phagocytophilum em equinos.

\begin{tabular}{lcccc}
\hline Regional & \multicolumn{4}{c}{ Titulação das amostras reativas $(\boldsymbol{\%}, \mathbf{n})$} \\
\cline { 2 - 4 } Barreiro & $1: 160$ & $1: 320$ & $1: 640$ & $1: 1280$ \\
Leste & $44,44(4 / 9)$ & $44,44(4 / 9)$ & $0,00(0 / 9)$ & $11,11(1 / 9)$ \\
Nordeste & $41,18(7 / 17)$ & $17,65(3 / 17)$ & $23,53(4 / 17)$ & $17,65(3 / 17)$ \\
Noroeste & $26,67(4 / 15)$ & $53,33(8 / 15)$ & $6,67(1 / 15)$ & $13,33(2 / 15)$ \\
Norte & $61,54(8 / 13)$ & $15,38(2 / 13)$ & $23,08(3 / 13)$ & $0,00(0 / 13)$ \\
Oeste & $16,67(2 / 12)$ & $33,33(4 / 12)$ & $25,00(3 / 12)$ & $25,00(3 / 12)$ \\
Pampulha & $65,00(13 / 20)$ & $15,00(3 / 20)$ & $15,00(3 / 20)$ & $5,00(1 / 20)$ \\
Venda Nova & $54,55(6 / 11)$ & $27,27(3 / 11)$ & $0,00(0 / 11)$ & $18,18(2 / 11)$ \\
Total & $26,09(6 / 23)$ & $43,48(10 / 23)$ & $21,74(5 / 23)$ & $8,70(2 / 23)$ \\
\hline
\end{tabular}


Com exceção das Regionais Norte e Leste, todas as Regionais apresentaram maior frequência de animais apresentando títulos mais baixos, apesar disto não se pode caracterizar estas como áreas de estabilidade enzoótica devido à porcentagem de amostras consideradas positivas, que deveriam estar acima de $80 \%$.

A diferença encontrada entre regionais pode ser explicada pela maior exposição à fatores de risco como presença de carrapatos, maior carga horária de trabalho quando comparado a outros animais de outras regionais, devido à maior demanda de recolhimento de entulho nas regionais Oeste e Venda Nova, que ainda apresentam grande crescimento urbano.

O percentual de animais sororreagentes com títulos acima de 1:640 foi de 41,18\% e 50,00\% nas Regionais Leste e Norte, respectivamente. Franzén et al. (2005) descreveram o pico da titulação entre três a sete dias após a soroconversão, correspondendo ao período entre 12 a 16 dias após infecção experimental. $\mathrm{O}$ que pode ser extrapolado para a situação em estudo e descrever os animais destas regionais com animais em fase de convalescença. Além disso, como as amostras foram obtidas durante o horário de trabalho dos animais, provavelmente os animais considerados positivos não apresentavam sintomatologia grave da doença.

Durante a avaliação das lâminas de capa leucocitária uma amostra foi considerada perdida e, assim, foram avaliadas 223 lâminas de esfregaço de capa leucocitária. Dentre os animais avaliados pelo esfregaço de capa leucocitária 3,14\% (7/223) possuíam inclusões indicativas da presença do agente (Figura 2). A Regional com o maior número de animais positivos foi a Norte $(10,00 \%$ - 3/30). As regionais Barreiro, Leste, Noroeste e Oeste não apresentaram nenhum animal considerado positivo, neste exame.

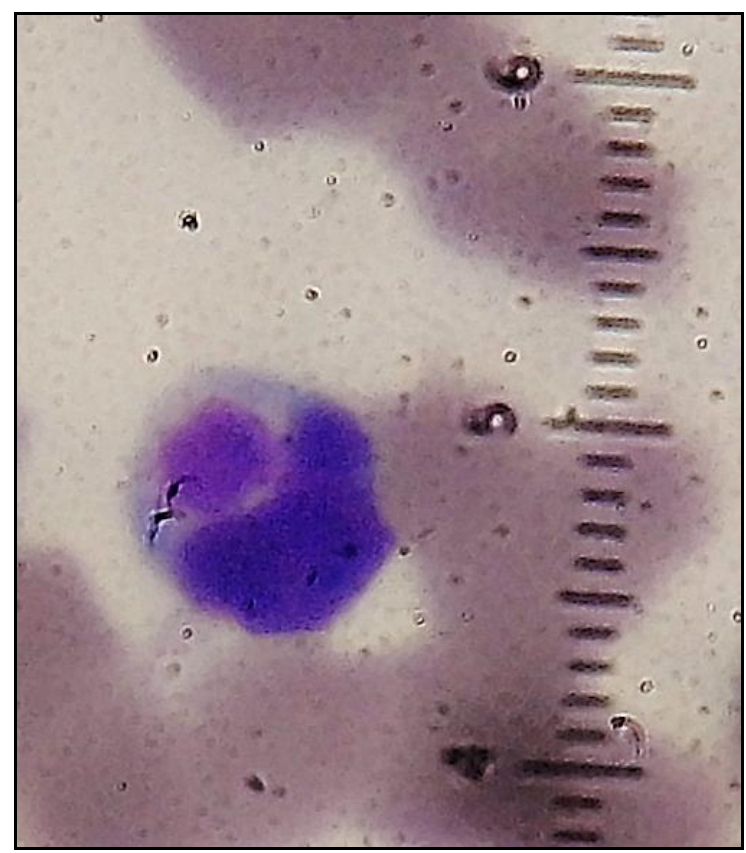

Figura 2 - Neutrófilo circulante apresentando inclusão intracitoplasmática sugestiva de mórula de Anaplasma phagocytophilum. Aumento 1000x.

A baixa ocorrência do exame direto encontrada no presente trabalho foi devida a coleta pontual. Segundo a literatura (STANNARD et al., 1969; BUTLER et al., 2008), as mórulas são normalmente encontradas durante a fase aguda e febril da doença. Durante os cursos e palestras ministradas, os carroceiros são orientados a não trabalharem com animais apresentando qualquer sintomatologia clínica. Recomenda-se encaminhá-los ao Hospital Veterinário da Escola de Veterinária da Universidade Federal de Minas Gerais (HV-EV/UFMG), onde serão devidamente avaliados e tratados de forma mais adequada. Assim, como as coletas foram realizadas nas URPVs e não no HV-EV/UFMG, o número de animais com sintomatologia clínica e consequentemente com presença de neutrófilos circulantes infectados, foi muito baixo.
Butler et al. (2008) descrevem em seu trabalho animais apresentando sintomatologia para AGE. Apesar de os sinais clínicos serem considerados inespecíficos, como febre, letargia, relutância ao andar e edema de membro, os animais avaliados no presente estudo parecem não apresentar os mesmos. Não foram realizados exames clínicos nos animais previamente à coleta, mas, por ser a coleta realizada durante o dia de trabalho dos animais, acredita-se que os mesmos não estivessem apresentando alterações que os impossibilitassem de trabalhar.

Dessas amostras, apenas seis $(6,25 \%)$ foram consideradas positivas para Anaplasma phagocytophilum (Figura 3). Por terem sido escolhidas ao acaso, não foi possível demostrar que os animais que apresentaram mórulas à avaliação da capa leucocitária também foram positivos para a avaliação pela PCR. 


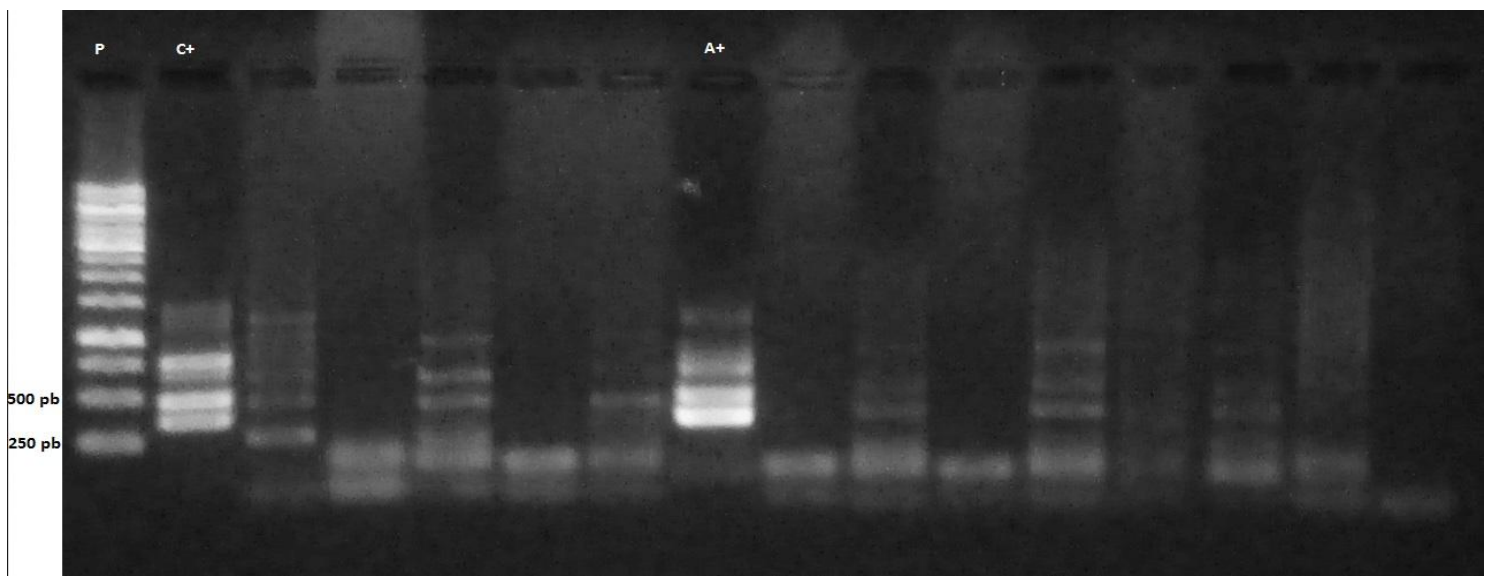

Figura 3 - Gel de Agarose 1\% apresentando amostra positiva para Anaplasma phagocytophilum. P: Padrão, peso molecular $1 \mathrm{~Kb}$; C+: Controle Positivo, obtido após extração de DNA de cultivo celular de A. phagocytophilum; A+: Amostra positiva; as duas últimas canaletas contém os brancos da primeira e da segunda reação, respectivamente.

\section{CONCLUSÃO}

Pode-se concluir que a infecção por $A$. phagocytophilum está presente em cavalos pertencentes ao "Projeto Carroceiros" no município de Belo Horizonte. Para que se entenda melhor qual a importância epidemiológica desta infecção para o município mais levantamentos sorológicos e moleculares, em equinos, devem ser realizados a fim de se entender melhor a dinâmica do agente na população equina.

A ocorrência de reação positiva na PCR demonstra que há a presença do agente nos animais de tração do município de Belo Horizonte, Minas Gerais.

\section{REFERÊNCIAS}

ANDRÉ, M. R.; DENARDI, N. C. B.; SOUSA, K. C. M.; GONÇALVES, L. R.; HENRIQUE, P. C.; ONTIVERO, C. R. G. R; GONZALES, I. H. L.; NERY, C. V. C.; CHAGAS, C. R. F.; MONTICELLI, C.; SANTIS, A. C. G. A; MACHADO, R. Z. Arthropod-borne pathogens circulating in free-roaminf domestic cats in a zoo environment in Brazil. Ticks and tick-borne Diseases, v. 5, n. 5, p. 545 - 551, 2014.

AGUIAR, D.M.; SAITO, T.B.; HAGIWARA, M.K.; MACHADO, R. Z.; LABRUNA, M. B. Diagnóstico sorológico de erliquiose canina com antígeno brasileiro de Ehrlichia canis. Ciência Rural, v. 37, n.3, p. 796802, 2007.

BAKKEN, J.S.; DUMLER, J.S.; CHEN, S. Human Granulocytic Ehrlichiosis In The Upper Midwest United States. A new species emerging? JAMA, v. 272, n. 3, p. 212-218, 1994.

BUTLER, C.M.; NIJHOF, A.M. JONGEJAN, F.; VAN DER KOLK, J. H. Anaplasma phagocytophilum infection in the Netherlands. The Veterinary Record, v. 162 , p. $216-218,2008$.
CARLYON, J.; FIRKING, E. Invasion and survival strategies of Anaplasma phagocytophilum. Cellular Microbiology., v.5, p.743-754, 2003.

DE LA FUENTE, J.; NARANJO, V.;RUIZ - FONS, F.; HÖFLE, U.; FERNANDEZ DE MERA, I, G.; VILLANUA, D.; ALMAZÁN, C.; TORINA, A.; CARACAPPA, S.; KOCAN, K. M.; GORTAZÁR, C. Potencial vertebrate reservoir hosts and invertebrate vectors of Anaplasma marginale and $A$. phagocytophilum in central Spain. Vector - borne and zoonotic diseases, v. 5, n. 4, p. 390-401, 2005.

DUMLER, J.S.; BARBET, A.F.; BEKKER, C.P.J.; DASCH, G. A.; PALMER, G. H.; RAY, S. C.; RIKIHISA, Y.; RURANGIRWA, F. R. Reorganization of genera in the families Rickettsiaceae and Anaplasmataceae in the order Rickettsiales: unification of some species of Ehrlichia with Anaplasma, Cowdria with Ehrlichia and Ehrlichia with Neorickettsia, descriptions of six new species combinations and designation of Ehrlicia equi and 'HE agent' as subjective synonyms of Ehrlichia phagocytophila. International Journal of Systematic and Evolutionary Microbiology, v. 51, p. 2145-2165, 2001.

FERREIRA, R. F.; CERQUEIRA, A. M. F.; PEREIRA, A. M.; VELHO, P. B.; AZEVEDO, R. R. M.; RODRIGUES, I. L. F.; ALMOSNY, N. R. P. Avaliação da ocorrência de reação cruzada em cães PCR-positivos para Anaplasma platys testados em ELISA comercial para detecção de anticorpos de Anaplasma phagocytophilum. Revistra Brasileira de Parasitologia, v. 17, supl. 1, o. 5-8, 2008.

FRANZÉN, P.; ASPAN, A.; EGENVALL, A.; GUNNARSSON, A.; ÁBERG, L.; PRINGLE, J. Acute clinical, hematological, serologic, and polymerase chain reaction findings in horses experimentally infected with a European strain of Anaplasma phagocytophilum. Journal of Veterinary Internal Medicine, v. 19, n. 2, p. 232-239, 2005. 
GIUDICE, E.; GIANNETTO, C.; FURCO, V.; ALONGI, A.; TORINA, A. Anaplasma phagocytophilum seroprevalence in equids: a survey in Sicily (Italy). Parasitology Research, v. 111, n. 2, p. $951-955,2012$.

GRIBBLE, D.H. Equine Ehrlichiosis. JAVMA, 155: 462-469, 1969.

HANSEN, M.G.B.; CHRISTOFFERSEN, M.; THUESEN, L.R.; PETERSEN, M. R.; BOJESEN, A. M. Seroprevalence of Borrelia burgdorferi sensu lato and Anaplasma phagocytophilum in Danish horses. Acta Veterinaria Scandinavica, v. 52, n. 3, p. $1-6$, 2010.

LEBLOND, A.; PRADIER, S.; PITEL, P. H.; FORTIER, G. BOIREAU, P. SABATIER, P. An epidemiological survey of equine anaplasmosis (Anaplasma phagocytophilum) in southern France. Revue Scientifique et Technique (International Office of Epizootics), v. 24, n. 3, p. 899 - 908, 2005.

MEZERVILLE, V. H.; PADILLA-CUADRA, J. I. Choque séptico por ehrlichiosis. Acta Medica Costarricense, v.49, p.118-120, 2007.

MONGRUEL, A. C. B.; BENEVENUTE, J. L.; ANDRÉ, M. R.; MACHADO, R. Z.; CARRASCO, A. O. T.; SEKI, M. C. Detection of Anaplasma sp. philogenetically related to A. phagocytophilum in a free-living bird in Brazil. Revista Brasileira de Parasitologia Veterinária. doi.org/10.1590/s198429612017042

PRASKOVA, I.; BEZDEKOVA, B.; ZEMAN, P.; JAHN, P. Seroprevalence of Anaplasma phagocytophilum in horses in the Czech Republic. Ticks and Tick-borne Diseases, v. 2, p. $111-115$, 2011.

PUSTERLA, N.; LEUTENEGGER, C.M.; CHAE, J.; LUTZ, H.; KIMSEY, R. B.; DUMLER, J. S.; MADIGAN, J. E. Quantitative evaluation of ehrlichial burden in horses after experimental transmission of Human granulocytic Ehrlichia Agent by intravenous inoculation with infected leucocytes and by infected ticks. Journal of Clinical Microbiology, v. 37, n. 12, p. 4042-4044, 1999.

RIBEIRO, A. J.; CARDOSO, L.; MAIA, J. M.; COUTINHO, T.; COTOVIO, M. Prevalence of Theileria equi, Babesia caballi, and Anaplasma phagocytophilum in horses from the north of Portugal. Parasitology Research, v. 112, n. 7, p. $2611-2617$, 2013.
SALVAGNI, C.A.; DAGNONE, A.S.; GOMES, T.S.; MOTA, J. S.; ANDRADE, G. M.; BALDANI, C. D.; MACHADO, R. Z. Serologic evidence of equine granulocytic anaplasmosis in horses from central West Brazil. Revista Brasileira de Parasitologia Veterinária, v. 19, n, 3, p. 135 - 140, 2010.

SANTOS, H.A.; THOMÉ, S. M. G.; BALDANI, C. D.; SILVA, C. B.; PREIXOTO, M. P.; PIRES, M. S.; VITARI, G. L. V.; COSTA, R. L.; SANTOS, T. M.; ANGELO, I. C.; SANTOS, L. A.; FACCINI, J. L. H.; MASSARD, C. L. Molecular epidemiology of the emerging zoonosis agent Anaplasma phagocytophilum (Fogie, 1949) in dogs and ixodid ticks. Parasites \& Vectors, v. 348, n. 6, 2013.

SILAGHI, C.; SANTOS, A. S.; GOMES, J.; CHRISTOVA, I.; MATEI, I. A.; WALDER, G.; DOMINGOS, A.; BELL-SAKYI, L.; SPRONG, H. VON LOEWENICH, F; D.; OTEO, J. A.; DE LA FUENTE, J.; DUMLER, J. S. Guidelines for the direct detection of Anaplasma spp. in diagnosis and epidemiological studies. Vector-borne and Zoonotic Diseases, v; 17, n. 1, p. 12 - 22, 2017.

SILVEIRA, J. A. G.; REIS, I. A.; ESTEVAM, L. G. T. M.; PINTO, MARINA, C. C.; ZWEYGARTH, E.; PASSOS, L. M. F.; PAZ, G. F. Important frequency of Anaplasma phagpcytophilum infection in a population of domiciled dogs in a urbanized area in south-easter Brazil. Pesquisa Veterinaria Brasileira, v. 37, n. 9, p. 958 - 962, 2017

STANNARD, A.A.; GRIBBLE. D.H.; SMITH, R.S. Equine Ehrlichiosis: A disease with similarities to tickborne fever and bovine petechial fever. The Veterinary Record, v. 84, n. 6, p. 149-150, 1969.

VON LOEWENICH, F.D.; STUMPF, G.; BAUMGARTEN, B.U.; RÖLLINGHOFF, M.; DUMLER, J. S.; BOGDAN, C. A case of Equine Granulocytic Ehrlichiosis provides molecular evidence for the presence of pathogenic Anaplasma phagocytophilum (HE agent) in Germany. European Journal of Microbiology and Infectious Disease, v. 22, n. 5, p. 303-305, 2003.

ZIMMERMAN, K.L.; CRISMAN, M.V. Diagnostic Equine Serology. Veterinary Clinics of North America: Equine, v. 24, n. 2, p. 311-334, 2008. 